\title{
Effects of Social Media Usage on the Speed of International Growth of an International New Venture
}

\author{
Sara Fraccastoro \\ University of Eastern Finland \\ sara.fraccastoro@uef.fi
}

\author{
Mika Gabrielsson \\ University of Eastern Finland \\ mika.gabrielsson@uef.fi
}

\begin{abstract}
The introduction of social media tools in entrepreneurial ventures has had a strong impact on their ability to access international networks, increase their competitiveness in foreign markets and improve their performance. Nevertheless, to the best of our knowledge, studies capturing the impact of social media usage on the internationalization process of International New Ventures (INVs) are lacking. We empirically analyze how social media usage influences the speed of the international growth of INVs in different phases of growth. Our results reveal that during the company's introductory phase, social media has a primary role in heightening the speed of internationalization. However, in more mature phases, the need for direct sales personnel and personal relationships increases. This ensures the company's insider position in international large account networks and guarantees a sustainable speed of international growth. Managerial implications are discussed as well as avenues for future research.
\end{abstract}

\section{Introduction}

International New Ventures (INVs), first theorized by Oviatt \& McDougall as companies, which "from the inception seek to derive significant competitive advantage from the use of resources and the sales of outputs in multiple countries" [24:49], have embodied a highly attractive research area among international business scholars over the past two decades $[5,19,24,25]$. INVs are able to overcome liabilities associated with the newness, foreignness and smallness of their operations thanks to the deployment of networks and different channels of internationalization [5, 6, 10, 44]. Nevertheless, the condition of belonging to a certain network has very often been taken for granted in the previous literature [8]. In fact, when the company is a start-up and lacks existing relationships in foreign markets, an internationalization approach via networking can be an arduous achievement.
Recent literature on international entrepreneurship suggests how the usage of social media can be leveraged to enter online networks and manage a wide set of international relationships, with the ultimate result of overcoming the "liability of outsidership" [17, 31]. Given the potentialities brought by the deployment of social media tools for a company's purposes, we are interested in analysing their effects on the speed of internationalization for INVs. Recent research has indeed called for further studies addressing the question of the speed of internationalization regarding INVs, which is so far under researched, and suggests paying particular attention to its dynamism $[2,4,10$, 27].

Only through a dynamic approach, tackled with longitudinal data, are we able to provide answers to the challenges that INVs face during their internationalization process which is often characterized by lack of resources $[27,38]$. The aim of this study is therefore to analyse the effects of social media usage on the speed of international growth of INVs during their development in international markets.

\section{Literature review}

\subsection{INVs and networks}

Literature on International New Ventures has found them to suffer from various liabilities, such as their smallness, newness and foreignness [19]. This means that when entering foreign markets, INVs suffer from a lack of resources (e.g. financial, technological, physical and intangible) due to their smallness, they lack reputation and legitimacy due to their newness [34] and knowledge about the business environment of the target market due to their foreignness [40, 41]. Prior literature indicates that networks are a way for INVs to overcome such liabilities $[5,25]$ and to grow in international markets $[5,6,44]$. 
Networks have been defined as a set of relationships between a firm and its external partners, such as customers, suppliers, agents and other similar social connections [3, 15,42]. A focal concept of the social network theory is embeddedness [13]. Granovetter [13] describes embeddedness as the level of involvement of an individual in the network. A high or low level of involvement in the network are respectively referred to as strong or weak ties. Strong ties represent close social relationships with a high frequency of contact; these links are often depicted by pre-existing (almost historic) relationships between the entrepreneur and his/her social partners $[12,22,37]$. Weak ties, on the other hand, are characterized by lower "amounts of time, intimacy and emotional intensity" of personal relationships [11:1361].

Literature on the effectiveness of ties of different strengths on the internationalization process of INVs is rich but at the same time divergent [5, 30,35]. This however testifies to the often-unpredictable behaviour of INVs and reflects arguments from the literature on entrepreneurship and internationalization [5].

Coviello [5] develops a model of network dynamics for INVs in the early-stages of internationalization. This research stresses the importance of the existence of network relationships already at an early phase (meaning before entering foreign markets and in some cases even earlier than the company's creation). Network embeddedness is therefore seen as a resource, which can be leveraged to gather knowledge about foreign markets and identify international opportunities $[9,17,39]$. Being integrated in one or more relevant networks makes the company an "insider" in that set of relationships [17:1415]. However, companies not located in foreign networks are seen as "outsiders" [ibid.]. As, Johanson and Vahlne [17] theorize, when a company attempts to enter a foreign market where it does not own a "relevant network position, it will suffer from the "liability of outsidership" and foreignness, and foreignness presumably complicates the process of being an insider" [17:1415]. In a recent study, Forsgren [8] emphasizes how in the business network theory, the condition of being an "insider" in a business network is given as an assumption. However, it very often happens that this precondition is not met, especially when the company is a new venture [8] or when the entrepreneur does not have previously established connections in foreign markets. Previous literature [10] has indeed found that the international connections deriving from former career experiences and affiliations of the entrepreneur to flow into the new venture and consequently enrich it with resources, which are fundamental for the introductory-phase. Laurell et al. [23] moreover argue that a diverse combination of networking activities during the early development of an INV leads to the creation of critical capabilities, which are useful in the firm's development. It is therefore arguable that new ventures, whose founders do not own a pre-existing and dispersed network of resources start with a disadvantage.

In 1973, Granovetter [11: 1378] shaped the concept of the "strength of weak ties", according to which "weak ties are seen as indispensable to individuals' opportunities and to their integration in a community". The strength of weak ties lies in enabling social actors to gather new information and bridge knowledge gaps, thanks to lower levels of intensity and higher levels of geographical dispersion. Very often, indeed, this new information is lacking in strong ties. Based on this concept, a recent body of literature emphasizes how weak relationships could be the most appropriate for international entrepreneurs when seeking and discovering international opportunities in foreign marketplaces and for successfully exploiting them $[9,31$, 32]. This becomes particularly relevant for International New Ventures which target international markets from their inception and suffer from a lack of resources $[10,24$, 26].

\subsection{The usage of Social Media in the internationalization process of INVs}

In a recent study on the usage of online social networks in international entrepreneurial ventures, Sigfusson and Chetty [31] find that social media, such as LinkedIn, are particularly useful for entrepreneurs managing a wide set of relationships identifiable as weak ties. In particular, they argue that social media enables entrepreneurs to be part of a wide online network, and allows them to increase their network identity through enhanced communication and to establish an "initial motive for trust" with other members of the network [31: 268]. This is in line with Fischer and Reuber [7], who find that entrepreneurial communication via social media can be used to reduce audience uncertainty about the firm and increase the differentiation from competitors. Moreover, by connecting with potential partners via social networking sites, entrepreneurs have the possibility of becoming insiders in strategic networks in foreign markets [31]. In this way, "the liability of outsidership" [17] is more easily overcome and international entrepreneurs gain relevant skills and resources to deploy when entering new markets [31].

Recent literature focuses on the opportunities brought from the usage of social media in some of the company's functions, such as sales and marketing. In particular, Andzulis et al. [1] discuss the implications of adopting social media in each step of the sales process. Lacoste [21] gives a thorough overview of social media usage by key account managers; while Guesalaga [14] proposes a 
model where the implementation of social media in the sales function is mainly triggered by organizational competence and commitment. Moreover, Rapp et al. [28] discuss the positive impact of social media adoption on the performance of B2B companies. From a marketing standpoint, in a recent study on time-varying effectiveness of social media and traditional marketing, Kumar et al. [20] show how these different marketing activities produce various results over time, by proposing an approach with a time-varying effect model, which helps save marketing costs.

It seems therefore clear that social media usage helps companies in saving costs related to marketing and sales; it enhances a firm's reputation and credibility in international markets, with the eventual results of overcoming the "liabilities of outsidership" [31] and boosting performance [28].

Despite these potentialities, there appears to be a paucity of studies regarding the implications of social media usage for the internationalization process of the company. Particularly, the relationship between social media usage and speed of international growth in the various growth phases of an INV remains unclear.

\subsection{The time dimension in international entrepreneurship}

The internationalization process of INVs has attracted researchers' attention over the past twenty years [10, 24, 29]. Despite being characterized by its dynamism, research in this field has mainly focused on sequences of entry modes in foreign markets and target market selection [2]. Only recently, with the emergence of international entrepreneurship as a further research focus, previously overlooked dimensions of the internationalization process, such as time and speed have started to receive scholars' attention [2,4,18, 27]. In particular, Casillas and Acedo [2] stress how the speed of internationalization has been often referred to as the time between the company's foundation and its first international activity. This perspective, however, highlights only the pre-internationalization period, leaving the process unexplored in its entirety [2]. As argued by Prashantam and Young [27], analysing not only the "initial speed", but also the "post- entry speed" helps understanding the chances of survival of an INV, as well as its long-term growth. More recently, Chetty et al. [4] tried to overcome such a scarce temporal perspective and offered a multidimensional conceptualization and operationalization of the concept of the speed of internationalization.

Adopting a temporal perspective in our study allows us to understand how the usage of social media changes over time and how it affects the speed of internationalization of the INV.

This becomes particularly relevant given the potential of social networking sites to challenge previous literature dealing with the structure and development of INVs' networks [31]. Moreover, despite that many INVs' relationships have been found to be dynamic and "process-based" [5:715, see also 15, 16, 22, 33], this dynamism seems not to be captured by the extant literature. In fact, as highlighted by Coviello [5], most of the studies in the field focus on entry modes in foreign markets and the firm's post-internationalization activities.

In Figure 1 we develop a conceptual framework where the theoretical dimensions introduced in the literature review are linked. In particular, the company's position in a relevant network determines the successful internationalization of an INV, as suggested in the previous literature [5,17]. However, in our model, we propose that the usage of social media plays a moderating role in this relationship. By allowing a newly established venture to enter and manage a large number of relationships, identifiable as weak ties [31], such usage enhances the firm's position in the networks and affect its speed of internationalization. We are particularly interested in looking at the dynamism of this phenomenon over time. Therefore, we develop propositions that look at this moderating effect along the growth phases of the INV in international markets. Given the novelty of the research and the undiscovered nature of the phenomena under observation, we follow a qualitative methodology.

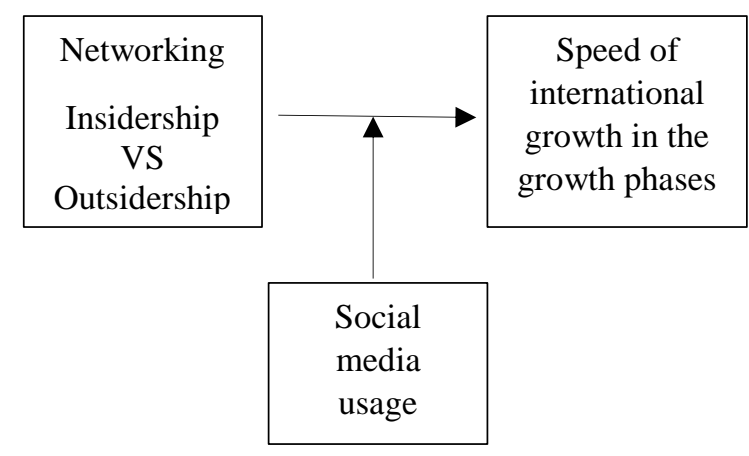

Figure 1. Conceptual framework

\section{Research methodology}

This study adopts a single longitudinal case-study approach [43] due to the exploratory nature of the 
research question and the novelty of the research area. This choice helps to analyse the complex role of social media and other networking means during the internationalization process phases of an INV. The relevance of choosing a longitudinal case-study lays in the possibility of explaining "how" and "why" change happens and therefore capturing dynamism [36, 43]. As suggested by Welch \& Paaivilainen-Mäntymäki [38], studies that stem from process theories, such as the internationalization process of INVs, should include process data. A case-study provides retrospective and real-time data which fit the description of firm internationalization well. Moreover, we follow Guesalaga [14: 78], who suggests that in order to capture the "time dynamics" in the usage of social media, it is advisable to analyse the phenomenon in one company, rather than the behaviour of many companies. We therefore capture the processual nature by designing the study longitudinally and analysing the same casecompany at different moments of its internationalization process [43].

\subsection{Beta CRM case study}

We selected the company from an international database listing exporting firms according to the country of origin and operating markets. The main criterion for the company selection was that the company should be an INV according to the definition by Oviatt \& McDougall, which "from inception seeks to derive significant competitive advantage from the use of resources and the sales of outputs in multiple countries" [24:49]. Second, the case company should have used social media, on-line applications and traditional networking means in the ordinary activities of its internationalization process. This choice helps us to understand the relevance of different media in diverse phases of internationalization. Third, we wanted a case company, which was some way ahead in its process of internationalization, so as to capture data at different stages of the firm's development and to be able to grasp their processual character. Last, but not least we wanted the company to commercialize a software-based service. This choice connects our research to other studies in this field [5, 30,31]. Taking into consideration these criteria, we selected an INV from Italy. The decision was motivated by the fact that Italy has a lower propensity for the adoption of web-related technologies than other European countries [45]. This could have offered counter-intuitive findings to our initial speculations. At the end of the selective process, we identified the company "Beta CRM", invited it to participate in the study and received positive feedback from the company. We collected primary data through a personal interview and repeated communications with the CEO and founder of the company; the data were complemented by extensive secondary data coming from the company's website, social media profiles and the company's blog, which covered the entire history of the firm. During the interview, we tried to thoroughly scrutinize our unit of analysis: the usage of social media to enter and activate network connections to accelerate the speed of international growth of an INV.

The interview was semi-structured and began with questions aimed at understanding the nature of the company, its products and the founders. When topics closer to the research focus approached, the researcher let the entrepreneur talk in an open manner. To ensure reliability, the interview was audio-recorded, stored in a database and transcribed verbatim with the permission of the informant. Moreover, the use of secondary data ensured the validity of the study. In Table 1, we provide a short description of the case company.

Table 1. Short description of the case company

\begin{tabular}{|c|c|}
\hline & Beta CRM \\
\hline Country of Origin & Italy \\
\hline Business sector & Online CRM software \\
\hline $\begin{array}{l}\text { Age; start of } \\
\text { internationalization }\end{array}$ & $\begin{array}{l}\text { 2013; immediate global } \\
\text { presence }\end{array}$ \\
\hline $\begin{array}{l}\text { Number of } \\
\text { countries served }\end{array}$ & $\begin{array}{l}\text { Worldwide presence; } \\
\text { approximately } 100 \\
\text { countries. }\end{array}$ \\
\hline $\begin{array}{l}\text { Number of } \\
\text { employees }\end{array}$ & 15 \\
\hline Headquarters & Treviso, (Italy) \\
\hline $\begin{array}{l}\text { Main channels of } \\
\text { internationalization }\end{array}$ & $\begin{array}{l}\text { App store, Facebook, Own } \\
\text { website, and sales } \\
\text { personnel }\end{array}$ \\
\hline Additional remarks & - \\
\hline
\end{tabular}

\section{Data analysis and proposition development}

In the following section, we provide an analysis of the data and we formulate our research propositions.

\subsection{The introductory phase of an INV and the usage of Social Media}

Beta CRM is a small Italian INV established in 2013 by two $\mathrm{PhD}$ graduates in computer science and an entrepreneur with managerial experience in an ICT 
multinational company. The company commercializes CRM software enabling sales force automation by simplifying the management of sales networks and sales activities. The company started its international activities since its inception, without experiencing a domestic phase. The internalization did not happen by accident, but was planned by the founding team. As one of the cofounders testified: "We immediately targeted international markets. We simply thought that selling software like ours in international markets would allow us to gain higher profitability".

Consistent with Gabrielsson et al. [10], at the moment of the company's creation, the founding team lacked substantial resources to quickly reach international markets. The team, however, had a strong degree of knowledge in ICT and marketing, given the previous academic experiences of the developers and the significant know-how in digital marketing of the third co-founder. As suggested by Gabrielsson et al. [10], these skills acted as human resources that led to the product development and search for channels of internationalization.

However, being a fledgling start-up company also contributed to a shortage of financial resources and to the lack of an established network of relationships across the world. This prevented the company from reaching international markets through a network approach alone $[5,6,10,44]$. Alternatively, the company decided to focus on social media channels to promote itself internationally. One of the co-founders explained the company's introductory phase as follows: "At the very beginning, the product was just an App [...]. Because of its international market potential, we immediately developed it as an international product. Therefore, we created one version of the App in Italian and one in English $[\ldots]$. We invested very little in marketing $[\ldots]$. We first marketed it on the App store, by optimizing the product's description through key words [...]. This allowed us to go fast on the market and to verify the product attractiveness [...]. We then started to be very active on Facebook, both from the social side and from the advertising side. This has increased the number of downloads all over the world at a low cost."

The use of social media and on-line related channels acted as alternative channel of internationalization. Reaching international markets was therefore easy, costeffective and lowered the risk of committing a great amount of resources internationally. In line with Sigfusson and Chetty [31], the company seemed to use social media to identify opportunities in the global markets and bridge relationship gaps. This was especially possible through the contact with potential buyers via social media, which lowered customers' uncertainty about the product and its quality [7]. We moreover found that the usage of social media enabled Beta CRM to reach global markets immediately after the company's creation and the product's commercialization. Thus, Proposition 1 is postulated as follows:

Proposition 1: The usage of social media in the introductory phase of an INV allows the company to efficiently reach weak network ties and through them enhances the speed of international growth.

\subsection{Sustainable growth in international markets.}

In accordance with Gabrielsson et al. [10], while growing in international markets, the company accumulated resources and knowledge about the external business environment and its initial customers. From this starting experience, the team decided to further develop the product and its range of usage. Indeed, since 2015, the product also became available on other operating systems and for computers. Such development allowed Beta CRM to target different business typologies, whereas the initial version allowed only targeting individual entrepreneurs and very small companies. However, targeting larger companies was different. In particular, the usage of social media was mainly attracting downloads from single workers, but left the big market segment of small, medium and large businesses unexplored. Therefore, in March 2015, simultaneously with the enlargement of its workforce and product development, Beta CRM started to change its strategy. Besides using social media and relying on the App store, the company started to advertise online and created a free-trial section on its website, where in-bound requests were encouraged by salespeople. One of the co-founders commented on this aspect as follows: "Using social media was less effective, when we tried to target bigger companies. Social media can be a component, but not the only one [...]. Therefore, we supported social media with content marketing such as search engine optimization and the creation of a free trial on the website [...]. Companies can now register on the website and our sales people assist them."

The combination of different marketing activities and the arrangement of salesperson support for customers visiting the website, allowed the company to build stronger network relationships with potential partners and customers. This change in strategy was mainly possible thanks to the resources and the knowledge acquired in the introductory phase, which sustained the company in its early phase of internationalization $[5,10]$. In this phase of the growth of the INV, the role of strong ties grew in importance over the weak ones and allowed the company to not only overcome the initial "liability of outsidership" $[17,31]$ but to actually start acquiring the position of insidership in the relevant network and 
quickly reached different business segments. Therefore, proposition 2 is formulated as:

Proposition 2: The combination of social media and other on-line channels in the growth phase of an INV allows the company to build stronger network ties, approaching more demanding business segments and allowing the company to enhance the speed of international growth.

\subsection{Long-term international growth.}

When experiencing growth in international markets and meeting small and medium sized businesses, Beta CRM faced the opportunity of serving very large customers coming from a number of diverse countries. However, along with the opportunity, the required level of commitment and resources to be invested also increased. One of the co-founders commented on this aspect as follows: "When we started to receive proposals from medium and large sized companies, we felt we needed a well-structured sales unit...because it becomes very difficult to sell via phone or online a product which becomes strategic for a company [...]. For example, we have a very big customer in Guatemala and there is big market potential, but if we do not create a sales unit there, which is able to meet the customer's expectations, it is hard to envisage that we would manage to pursue that goal $[\ldots]$. Therefore, since this year, we will physically reach other countries."

Gabrielsson et al [10: 397], refer to this INV's strategy as to "break-out". In this growth phase, the INV increasingly deploys organizational learning and knowledge coming from its network partners, such as global customers and competitors. This allows the company to further strengthen its network position with key customers and to break-out from constraining network dependencies, such as in this case the App store, Google Apps and even the firm's own on-line store. This finally allowed the INV to strengthen its insider position in the network and continue to grow internationally at a fast pace. These findings are moreover in line with Partanen et al. [26], who found that along with incremental-systemic innovations, the importance of strong network ties increases. In Beta CRM, these latter can be identified with improved technology and heightened levels of services for key customers.

In this last phase, we can notice, moreover, how the role of social media shifts from being very central -as in the introductory phase- to being of support to the continuous generation of new business opportunities. The third proposition is therefore postulated as follows:
Proposition 3: On-line tools including social media take on a supporting role in the break-out growth phase of an INV. The usage of direct sales personnel becomes a necessity to build strong networks and a truly insider position within large accounts, allowing a sustainable speed of international growth.

\section{Discussions and conclusions}

By analysing the effects of social media usage on the speed of international growth during the development phases of an INV, this article brings new insights to a research area which has been covered only to a limited extent by previous studies $[2,4,27]$. We found that the usage of social media in the introductory phase of the company helps the firm in developing international relations and increases the speed of international growth, despite an initial lack of resources and a dearth of established network relationships $[5,10]$. This is in line with previous research by Sigfusson and Chetty [31] who found that social media enabled entrepreneurial ventures to successfully manage their relationships in international markets. We moreover found that, after the company has acquired relevant resources and knowledge from its external business environment, it continues developing its products and tries to enlarge its network relationships through the combined usage of social media and other online activities. This allows the INV to gain a position of insidership in the relevant network and to identify diverse opportunities in larger business segments. During this more advanced phase of internationalisation, network relationships acquire increasing significance for the company. This further enhances the speed of international growth of the INV.

When approaching more mature phases, we found the INV to be increasingly connected to the surrounding business networks and therefore holding a position of a "true insider". In line with Gabrielsson et al [10], in this phase the INV increases the level of resource commitment towards international markets as well as increasing personal involvement with international customers. These findings are in line also with Partanen et al. [26] who found that in order to successfully commercialize incremental-systemic innovations, strong collaborative network ties with customers are required. The usage of social media here plays only a support role to more traditional ways of networking. These last steps are the principal determinant of higher long-term speed in international growth.

By adopting a temporal perspective in our study, we have shed light on a research topic, for which further studies have been called [2,4,31]. We have found important implications for international entrepreneurship and networking literature. 
We believe the study to be helpful for founders and entrepreneurs of INVs. In particular, for those firms trying to reach international markets, but affected by a lack of resources [24] and a lack of previously established connections in foreign markets [8]. The study is moreover helpful for companies at a more mature phase of their development. From a networking standpoint, we traced previous literature dealing with the topic and provided insights on how the network dynamics of INVs change over time [5, 23,26]. Moreover, we contributed to the literature by being specific about how social media usage influences the speed of the international growth of INVs in different phases of their development.

Given its qualitative nature, the study is limited in terms of the generalizability of the results to the typology of firm investigated. However, to the extent that the starting conditions are similar in other business endeavours and industries, the results may be extended to other contexts. This opens avenues for future studies in the area, where the effects of the usage of social media on the speed of the international growth of companies coming from different industries and commercialising diverse products could be analysed. Moreover, our results are based on a case-study coming from Italy, which is a large economy. Future studies based on other countries (e.g. coming from small and open economies) are called for, in order to validate the suggested framework and propositions. Diverse methodological approaches could also be implemented to further analyse the topic. Through qualitative data we were able to develop theory [43], however through future quantitative studies we would acquire statistical generalizations.

\section{References}

[1] Andzulis, J. M., Panagopoulos, N. G., \& Rapp, A. (2012). A review of social media and implications for the sales process. Journal of Personal Selling \& Sales Management, 32(3), 305316.

[2] Casillas, J. C., \& Acedo, F. J. (2013). Speed in the internationalization process of the firm. International Journal of Management Reviews, 15(1), 15-29.

[3] Chetty, S., \& Agndal, H. (2007). Social capital and its influence on changes in internationalization mode among small and medium-sized enterprises. Journal of International Marketing, 15(1), 1-29.

[4] Chetty, S., Johanson, M., \& Martín, O. M. (2014). Speed of internationalization: Conceptualization, measurement and validation. Journal of World Business, 49(4), 633-650.
[5] Coviello, N. E. (2006). The network dynamics of international new ventures. Journal of International Business Studies, 37(5), 713-731.

[6] Coviello, N., \& Munro, H. (1997). Network relationships and the internationalisation process of small software firms. International business review, 6(4), 361-386.

[7] Fischer, E., \& Reuber, A. R. (2014). Online entrepreneurial communication: Mitigating uncertainty and increasing differentiation via Twitter. Journal of Business Venturing, 29(4), 565-583.

[8] Forsgren, M. (2016). A note on the revisited Uppsala internationalization process model-the implications of business networks and entrepreneurship. Journal of International Business Studies, 47(9), 1135-1144.

[9] Forsgren, M., Holm, U., \& Johanson, J. (2015). Knowledge, Networks and Power-The Uppsala School of International Business. In Knowledge, Networks and Power (pp. 3-38). Palgrave Macmillan UK.

[10] Gabrielsson, M., Kirpalani, V. M., Dimitratos, P., Solberg, C. A., \& Zucchella, A. (2008). Born globals: Propositions to help advance the theory. International Business Review, 17(4), $385-401$.

[11] Granovetter, M. (1973). The strength of weak ties. American Journal of Sociology, 78:1360-1380.

[12] Granovetter, M. (1982). The strength of weak ties: A network theory revisited. In P. V. Marsden \& N. Lin (Eds.), Social structure and network analysis (pp. 105-130). Beverly Hills, CA: Sage.

[13] Granovetter, M. (1985). Economic action and social structure: The problem of embeddedness. American journal of sociology, 91(3), 481-510.

[14] Guesalaga, R. (2016). The use of social media in sales: Individual and organizational antecedents, and the role of customer engagement in social media. Industrial Marketing Management, 54, 71-79.

[15] Hite, J. M., \& Hesterly, W. S. (2001). The evolution of firm networks: From emergence to early growth of the firm. Strategic management journal, 22(3), 275-286.

[16] Hoang, H., \& Antoncic, B. (2003). Network-based research in entrepreneurship: A critical review. Journal of business venturing, 18(2), 165-187.

[17] Johanson, J., \& Vahlne, J. E. (2009). The Uppsala internationalization process model revisited: From liability of foreignness to liability of outsidership. Journal of international business studies, 40(9), 1411-1431.

[18] Jones, M. V., \& Coviello, N. E. (2005).

Internationalisation: conceptualising an entrepreneurial process 
of behaviour in time. Journal of International Business Studies, 36(3), 284-303.

[19] Knight, G. A., \& Cavusgil, S. T. (2004). Innovation, organizational capabilities, and the born-global firm. Journal of International Business Studies, 35, 124-141.

[20] Kumar, V., Choi, J. B., \& Greene, M. (2017). Synergistic effects of social media and traditional marketing on brand sales: capturing the time-varying effects. Journal of the Academy of Marketing Science, 1-21.

[21] Lacoste, S. (2016). Perspectives on social media ant its use by key account managers. Industrial Marketing Management, $54,33-43$.

[22] Larson, A., \& Starr, J. A. (1993). A network model of organization formation. Entrepreneurship: Theory and Practice, 17(2), 5-16.

[23] Laurell, H., Achtenhagen, L., \& Andersson, S. (2015). The changing role of network ties and critical capabilities in an international new venture's early development. International Entrepreneurship and Management Journal, 1-28.

[24] Oviatt, B. M., \& McDougall, P. P. (1994). Toward a theory of international new ventures. Journal of international business studies, 45-64.

[25] Oviatt, B. M., \& McDougall, P. P. (2005). The internationalization of entrepreneurship. Journal of International Business Studies, 36(1), 2-8.

[26] Partanen, J., Chetty, S., \& Rajala, A. (2011). Innovation types and network relationships. Entrepreneurship Theory and Practice, 35(3), 1-29.

[27] Prashantham, S., \& Young, S. (2011). Post-Entry Speed of International New Ventures. Entrepreneurship Theory and Practice, 35(2), 275-292.

[28] Rapp, A., Beitelspacher, L. S., Grewal, D., \& Hughes, D. E. (2013). Understanding social media effects across seller, retailer, and consumer interactions. Journal of the Academy of Marketing Science, 41(5), 547-566.

[29] Rialp, A., Rialp, J., \& Knight, G. A. (2005). The phenomenon of early internationalizing firms: what do we know after a decade (1993-2003) of scientific inquiry? International business review, 14(2), 147-166.

[30] Sharma, D. D., \& Blomstermo, A. (2003). The internationalization process of born globals: a network view. International business review, 12(6), 739-753.

[31] Sigfusson, T., \& Chetty, S. (2013). Building international entrepreneurial virtual networks in cyberspace. Journal of World Business, 48(2), 260-270.
[32] Sigfusson, T., \& Harris, S. (2012). The relationship formation paths of international entrepreneurs. Journal of International Entrepreneurship, 10(4), 325-349.

[33] Slotte-Kock, S., \& Coviello, N. (2010). Entrepreneurship research on network processes: A review and ways forward. Entrepreneurship Theory and Practice, 34(1), 31-57.

[34] Stinchcombe, A. L., \& March, J. G. (1965). Social structure and organizations. Advances in strategic management, 17, 229-259.

[35] Söderqvist, A., \& Kamala Chetty, S. (2013). Strength of ties involved in international new ventures. European Business Review, 25(6), 536-552.

[36] Van de Ven, A. H., \& Poole, M. S. (1995). Explaining development and change in organizations. Academy of management review, 20(3), 510-540.

[37] Walker, G., Kogut, B., \& Shan, W. (1997). Social capital, structural holes and the formation of an industry network. Organization science, 8(2), 109-125.

[38] Welch, C., \& Paavilainen-Mäntymäki, E. (2014). Putting process (back) in: research on the internationalization process of the firm. International Journal of Management Reviews, 16(1), 2-23.

[39] Wiedersheim-Paul, F., Olson, H. C., \& Welch, L. S. (1978). Pre-export activity: The first step in internationalization. Journal of International Business Studies, 9(1), 47-58.

[40] Zaheer, S. (1995). Overcoming the liability of foreignness. Academy of Management journal, 38(2), 341-363.

[41] Zaheer, S. (2002). The liability of foreignness, redux: A commentary. Journal of International Management, 8(3), 351358.

[42] Zhou, L., Wu, W. P., \& Luo, X. (2007). Internationalization and the performance of born-global SMEs: the mediating role of social networks. Journal of international business studies, 38(4), 673-690.

[43] Yin, R. K. (2009). Case study research: Design and methods. 4 uppl. Thousand Oaks, CA.

[44] Yli-Renko, H., Autio, E., \& Tontti, V. (2002). Social capital, knowledge, and the international growth of technologybased new firms. International Business Review, 11(3), 279304.

[45] https://ec.europa.eu/digital-single-market/en/desi. 